\title{
INFLUENCE OF COPPER ON ELECTRICAL CONDUCTIVITY OF GLASS-CERAMICS BASED ON VANADIUM DIOXIDE
}

\author{
A.I. Ivon*, V.R. Kolbunov \\ Oles Honchar Dnipro National University, Dnipro, Ukraine \\ e-mail:a_ivon@mail.ru
}

The results of studying the electrical conductivity $\sigma$ for the glass-ceramic systems $\mathrm{VO}_{2}$-vanadiumphosphate glass (VPG) and $\mathrm{VO}_{2}-\mathrm{VPG}-\mathrm{SnO}_{2}$ with the additions of $\mathrm{Cu}$ and $\mathrm{Cu}_{2} \mathrm{O}$ are presented. It is found that the jump of conductivity at the temperature of metal-semiconductor phase transition (MSPT) in $\mathrm{VO}_{2}$ $\left(T_{t}=341 \mathrm{~K}\right)$ takes place only for glass-ceramics containing not more than $5 \mathrm{wt} \%$ of these additives. When their content exceeds $5 \mathrm{wt} \%$, the $\mathrm{VO}_{2}$ content decreases sharply according to the data of differential thermal analysis. The reason for this is the oxidation-reduction reactions in the liquid phase between $\mathrm{Cu}$ and $\mathrm{VO}_{2}$ at ceramics synthesis. These reactions result in the appearance of Magneli phases in glass-ceramics composition. The phase transitions in Magneli phases $\mathrm{V}_{4} \mathrm{O}_{7}, \mathrm{~V}_{5} \mathrm{O}_{9}$, and $\mathrm{V}_{6} \mathrm{O}_{13}$ are indicated by the temperature dependence of $\sigma$, as bends of the straight lines in coordinates $\log _{10} \sigma \sim 1 / \mathrm{T}$ at the phase transition temperatures $T_{t}$ of these phases: $240 \mathrm{~K}, 150 \mathrm{~K}$, and $130 \mathrm{~K}$. The activation energy of $\sigma$ for $T>T t$ is lower than for $\mathbf{T}<\mathrm{Tt}$, which indicates a change in the structure of energy zones inherent to MSPT.

Keywords: glass-ceramics, electrical conductivity, metal-semiconductor phase transition, vanadium dioxide, Magneli phases.

Received 08.09.2019; Received in revised form 14.10.2019; Accepted 15.10.2019

\section{Introduction}

Glass-ceramic materials based on vanadium dioxide $\left(\mathrm{VO}_{2}\right)$ - vanadium-phosphate glass (VPG) system have the abrupt change in electrical conductivity near the temperature $T_{t}=$ $341 \mathrm{~K}$. This change is $2-3$ orders of magnitude and is a consequence of the metalsemiconductor phase transition (MSPT) in $\mathrm{VO}_{2}$ [1]. This allows using such materials in critical thermistors that combine the properties of a conventional thermistor with a negative temperature coefficient of resistance and a thermal relay. Such thermistors can be used to protect power supplies and incandescent lamps from turn-on currents effectively [2, 3]. The electrical conductivity $\sigma$ of glass-ceramics in the $\mathrm{VO}_{2}-\mathrm{VPG}$ system and the magnitude of the jump $\sigma$ in the region of MSPT in $\mathrm{VO}_{2}$ can be controlled by the additives of copper, $\mathrm{Cu}_{2} \mathrm{O}$ and tin dioxide $\mathrm{SnO}_{2}$ [1, 4]. It is shown in [4], that at the synthesis of glass-ceramics in $\mathrm{VO}_{2}-\mathrm{VPG}-\mathrm{SnO}_{2}$ system, the VPG in a liquid phase is chemically neutral to $\mathrm{VO}_{2}$ and $\mathrm{SnO}_{2}$. According to the data of scanning electron microscopy and X-ray phase analysis [1, 4], the glass-ceramics of $\mathrm{VO}_{2}-\mathrm{VPG}$ system contains $\mathrm{VO}_{2}$ crystallites, and the glass-ceramics of $\mathrm{VO}_{2}-\mathrm{VPG}-\mathrm{SnO}_{2}$ system contains $\mathrm{VO}_{2}$ and $\mathrm{SnO}_{2}$ crystallites. $\mathrm{VO}_{2}$ crystallites have sizes from 3.5 to $50 \mu \mathrm{m}$, and $\mathrm{SnO}_{2}$ crystallites have sizes from 5 to $17 \mu \mathrm{m}$. VPG forms layers with the thickness of 1-2 microns in the space between crystallites. Vanadium dioxide dissolves in the liquid phase at glass-ceramics synthesis, which contributes to the growth of its crystallites.

The introduction of $\mathrm{Cu}$ and $\mathrm{Cu}_{2} \mathrm{O}$ into the $\mathrm{VO}_{2}-\mathrm{VPG}$ and $\mathrm{VO}_{2}-\mathrm{VPG}-\mathrm{SnO}_{2}$ systems significantly changes the electrical conductivity, phase composition, and microstructure of glass-ceramics. In its X-ray spectra the lines appear that were identified by JCPDS files as Magneli phases: $\mathrm{V}_{3} \mathrm{O}_{5}, \mathrm{~V}_{4} \mathrm{O}_{7}, \mathrm{~V}_{5} \mathrm{O}_{9}, \mathrm{~V}_{6} \mathrm{O}_{11}, \mathrm{~V}_{4} \mathrm{O}_{9}, \mathrm{~V}_{6} \mathrm{O}_{13}$ [4]. The intensity of the $\mathrm{VO}_{2}$ lines in $\mathrm{X}$-ray spectra decreases when $\mathrm{Cu}$ and $\mathrm{Cu}_{2} \mathrm{O}$ contents grow. Such behavior of $\mathrm{VO}_{2}$ lines and the appearance of Magneli phases indicate a chemical interaction between copper and vanadium dioxide at the synthesis of glass-ceramics. Since according to the data of X-ray microanalysis, $\mathrm{Cu}$ and $\mathrm{VO}_{2}$ dissolve in the liquid phase, such interaction may be a consequence of oxidation-reduction reactions between them. This is confirmed by the appearance of $\mathrm{CuO}$ lines in the X-ray spectra of glass-ceramics after its synthesis [4]. As is known [5], at low temperatures the Magneli phases have MSPT with a jump of electrical conductivity. This transition is associated with a change in the structure of energy zones and 
it can give a contribution to the low-temperature electrical conductivity of $\mathrm{VO}_{2}$ based glass-ceramics with the additions of $\mathrm{Cu}$ and $\mathrm{Cu}_{2} \mathrm{O}$. In this connection, the aim of this work is to study the electrical conductivity of glass-ceramics in systems $\mathrm{VO}_{2}-\mathrm{VPG}$ and $\mathrm{VO}_{2}-\mathrm{VPG}-\mathrm{SnO}_{2}$ with the additives of $\mathrm{Cu}$ and $\mathrm{Cu}_{2} \mathrm{O}$ in a wide temperature range.

\section{Samples and methods of investigation}

The vanadium-phosphate glass of composition (mol.\%) $80 \mathrm{~V}_{2} \mathrm{O}_{5}-20 \mathrm{P}_{2} \mathrm{O}_{5}$ and $\mathrm{VO}_{2}$ are the basic components of glass-ceramics. Vanadium-phosphate glass was obtained according to the technology described in [6]. Crystalline vanadium dioxide was obtained by means of $\mathrm{V}_{2} \mathrm{O}_{5}$ reducing with carbon in a neutral gas atmosphere [7]. [1, 4] describe the technology that was used for producing glass-ceramic samples $(85-\alpha) \mathrm{VO}_{2}-15 \mathrm{VPG}-\alpha \mathrm{Cu}$ with $\alpha$ in the range of $0 \mathrm{wt} \% \leq \alpha \leq 15 \mathrm{wt} \%$ and $40 \mathrm{VO}_{2}$ $15 \mathrm{VPG}-\alpha \mathrm{Cu}_{2} \mathrm{O}-(45-\alpha) \mathrm{SnO}_{2}$ with $\alpha$ in the range of $0 \mathrm{wt} \% \leq \alpha \leq 10 \mathrm{wt} \%$.

Samples for studying the temperature dependence of electrical conductivity had a disk shape with a base diameter of $10 \mathrm{~mm}$ and a thickness of $2 \mathrm{~mm}$. Electrodes for the samples were created by copper electrodeposition.

The temperature dependence of electrical conductivity at low temperatures was measured in an alcohol cryostat at heating rate of the test sample not more than $1 \mathrm{~K} / \mathrm{min}$. Measurements in the temperature range $290 \mathrm{~K}-400 \mathrm{~K}$ were performed in an electric furnace with heating rate not more $1.5 \mathrm{~K} / \mathrm{min}$. For temperature measurements with an absolute error no more than $\pm 0.5 \mathrm{~K}$ the copper resistance thermometer was used. The sample resistance was measured with a relative error of $\pm 1 \%$ by means of a direct-current bridge MO-62.

The data of differential thermal analysis (DTA) were used for the measurement of $\mathrm{VO}_{2}$ content in studied glass-ceramics according to the method described in [8]. The $\mathrm{VO}_{2}$ content was determined by comparing the areas of endothermic peaks in DTA curves near the temperature $341 \mathrm{~K}$ for the glass-ceramics and vanadium dioxide crystals. DTA measurements were performed on instrument OD-103A in the temperature range $290 \mathrm{~K}-$ $420 \mathrm{~K}$ at a heating rate of $1.25 \mathrm{~K} / \mathrm{min}$.

\section{Experimental results and discussion}

Fig. 1 shows the temperature dependences of the specific conductivity $\sigma$ for glassceramics $40 \mathrm{VO}_{2}-15 \mathrm{VPG}-\alpha \mathrm{Cu}_{2} \mathrm{O}-(45-\alpha) \mathrm{SnO}_{2}$ with different content of $\mathrm{Cu}_{2} \mathrm{O}$. As it can be seen, the jump of conductivity at $341 \mathrm{~K}$, associated with the MSPT in $\mathrm{VO}_{2}$, is observed only for compositions containing no more than $5 \mathrm{wt} \% \mathrm{Cu}_{2} \mathrm{O}$. In compositions with $\mathrm{Cu}_{2} \mathrm{O}$ content of $8 \mathrm{wt} \%$ or more, such jump is absent. The reason for this may be the absence of percolation through $\mathrm{VO}_{2}$ phase due to its low content. This is confirmed by the Fig. 2, which shows the dependences of the $\mathrm{VO}_{2}$ content in the mixture for the manufacture of glass-ceramic (wt\%) $(85-\alpha) \mathrm{VO}_{2}-15 \mathrm{VPG}-\alpha \mathrm{Cu}$ before (curve 1) and after (curve 2) ceramics synthesis. It is follows from Fig. 2 data, that the content of vanadium dioxide in glass-ceramics sharply decreases when the content of $\mathrm{Cu}$ additive exceeds $5 \mathrm{wt} \%$. When the content of $\mathrm{Cu}$ is $15 \mathrm{wt} \%$, the $\mathrm{VO}_{2}$ content does not exceed $1.5 \mathrm{wt} \%$. A decrease in the $\mathrm{VO}_{2}$ content with an increase in the copper content is probably a consequence of the oxidation-reduction reactions between these components, since the liquid phase at the ceramics synthesis contains dissolved $\mathrm{VO}_{2}$ and $\mathrm{Cu}$. This is confirmed by the appearance of the $\mathrm{CuO}$ lines in $\mathrm{X}$-ray spectra of glass-ceramics when the content of $\mathrm{Cu}_{2} \mathrm{O}$ exceeds 7 wt $\%$ [4]. As the result of the reaction $\mathrm{nVO}_{2}+\mathrm{Cu} \rightarrow \mathrm{V}_{\mathrm{n}} \mathrm{O}_{2 \mathrm{n}-1}+\mathrm{CuO}$, the Magneli phases with the general formula $\mathrm{V}_{\mathrm{n}} \mathrm{O}_{2 \mathrm{n}-1}$ may crystallize in the liquid phase during the glassceramics synthesis. The presence of such phases in ceramics on the basis of $\mathrm{VO}_{2}$ with a high copper content was confirmed by X-ray phase analysis [4]. 


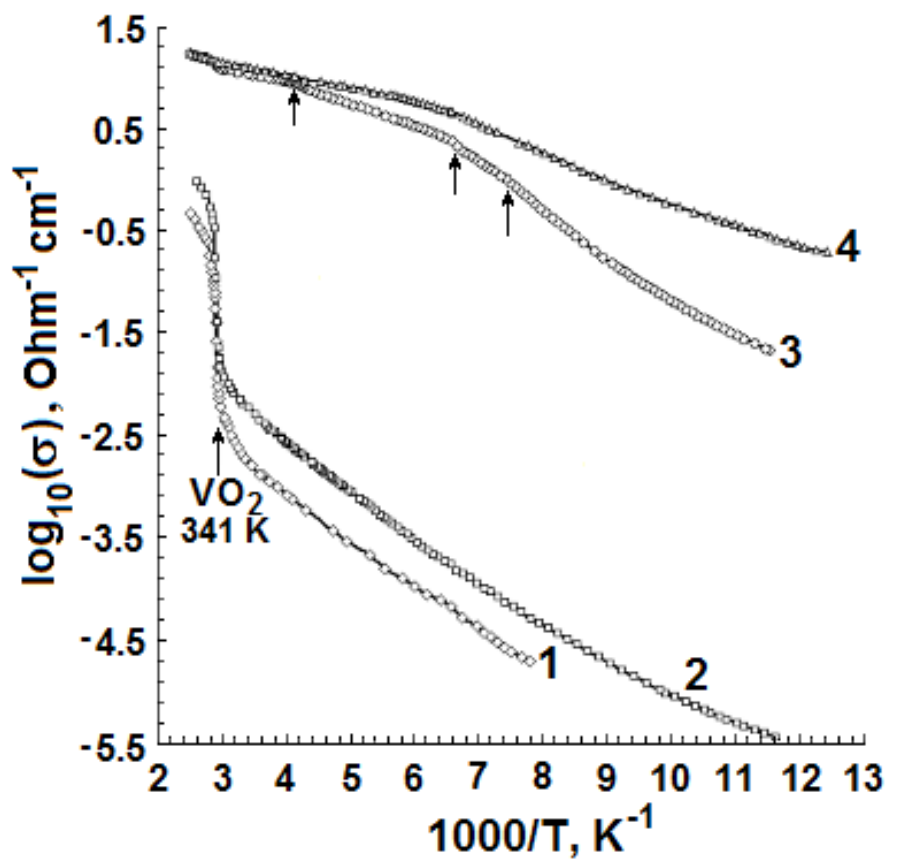

Fig. 1. Temperature dependences of the specific electrical conductivity of glass-ceramics 40VO ${ }_{2}-15 \mathrm{VPG}-\alpha \mathrm{Cu}_{2} \mathrm{O}-(45-\alpha) \mathrm{SnO}_{2}$ with $\mathrm{Cu}_{2} \mathrm{O}$ content $\alpha(\mathrm{wt} \%): 1-2 ; 2-5 ; 3-8 ; 4-10$.

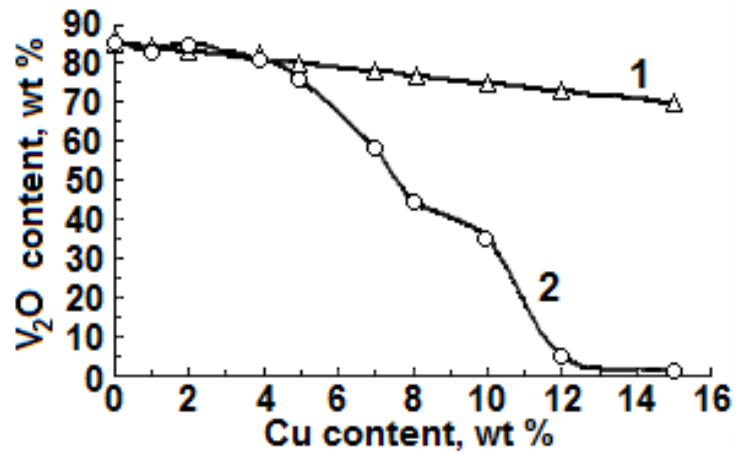

Fig. 2. Dependence of $\mathrm{VO}_{2}$ content on copper content $\alpha$ for glass-ceramics $(85-\alpha) \mathrm{VO}_{2}-15 \mathrm{VPG}-\alpha \mathrm{Cu}$ in the initial mixture (1) and after synthesis (2)

The values of the MSPT temperature $T_{t}$ for some phases of Magneli, according to different authors, are shown in the Tab. 1.

Table 1

Metal-semiconductor phase transition temperature for some vanadium oxides

\begin{tabular}{|c|c|c|}
\hline Compound & $\begin{array}{c}\text { Temperature of MSPT T } \\
\mathbf{K}\end{array}$ & $\begin{array}{c}\text { Change in conductivity at } \\
\text { MSPT temperature [5] }\end{array}$ \\
\hline $\mathrm{VO}_{2}$ & $340[5]$ & $10^{5}$ \\
$\mathrm{~V}_{3} \mathrm{O}_{5}$ & $450[5]$, & $10^{2}$ \\
$\mathrm{~V}_{4} \mathrm{O}_{7}$ & $240[5], 237[9]$ & $10^{3}, 10^{2}[9]$ \\
$\mathrm{V}_{5} \mathrm{O}_{9}$ & $130[5], 129[11]$ & $10^{6}$ \\
$\mathrm{~V}_{6} \mathrm{O}_{13}$ & $150[5], 153[10]$ & $10^{6}$ \\
\hline
\end{tabular}


As it can be seen in Fig. 1, a significant increase in electrical conductivity $\sigma$ takes place with increasing $\mathrm{Cu}_{2} \mathrm{O}$ content in ceramics $40 \mathrm{VO}_{2}-15 \mathrm{VPG}-\alpha \mathrm{Cu}_{2} \mathrm{O}-(45-\alpha) \mathrm{SnO}_{2}$. The temperature dependence $\sigma$ in the Arrhenius coordinates for the samples with a high $\mathrm{Cu}$ content shows bends for the straight line in coordinates $\log _{10} \sigma \sim 1 / \mathrm{T}$ at certain temperatures (temperatures are indicated by arrows in Fig. 1). These bends show a transition from higher values of activation energy to lower values with temperature increasing. This behavior is not typical for semiconductor materials, the electrical conductivity of which is determined by donor or acceptor levels, and indicates a change in the energy structure of zones at temperatures corresponding to the bends. As it is known [5], a change in energy structure of zones occurs at the metal-semiconductor phase transitions. For such transitions at the temperature of MSPT $T_{t}$, the character of temperature behavior of electrical conductivity changes from the activation behavior to the metallic behavior with temperature increasing. This is accompanied by a sharp increase in electrical conductivity.

It follows from the data in Fig. 1 that the glass-ceramics with composition $40 \mathrm{VO}_{2}-$ $15 \mathrm{VPG}-8 \mathrm{Cu}_{2} \mathrm{O}-37 \mathrm{SnO}_{2}$ shows the most evident bends of the linear dependence $\log _{10} \sigma \sim$ 1/T. In Fig. 3 the temperature dependences of electric conductivity for this ceramics are shown in the Arrhenius coordinates in the region of the bend temperatures. Table 2 shows the activation energies of $\sigma$ below and above the temperature corresponding to a bend in the dependence $\log _{10} \sigma \sim 1 / \mathrm{T}$.

Table 2

The activation energy of electrical conductivity for glass-ceramics (wt \%) $40 \mathrm{VO}_{2}-15 \mathrm{VPG}-8 \mathrm{Cu}_{2} \mathrm{O}-37 \mathrm{SnO}_{2}$ in the temperature range of the bend in dependence on $\log _{10} \sigma \sim 1 / \mathrm{T}$

\begin{tabular}{|c|c|c|c|c|c|c|}
\hline Magneli phase & \multicolumn{2}{|c|}{$\mathrm{V}_{4} \mathrm{O}_{7}$} & \multicolumn{2}{c|}{$\mathrm{V}_{6} \mathrm{O}_{13}$} & \multicolumn{2}{c|}{$\mathrm{V}_{5} \mathrm{O}_{9}$} \\
\hline $\begin{array}{c}\text { Temperature } \\
\text { range, } \mathbf{K}\end{array}$ & $\mathrm{T}>240$ & $\mathrm{~T}<240$ & $\mathrm{~T}>150$ & $\mathrm{~T}<150$ & $\mathrm{~T}>130$ & $\mathrm{~T}<130$ \\
\hline $\begin{array}{c}\text { Activation } \\
\text { energy, eV }\end{array}$ & 0.021 & 0.041 & 0.042 & 0.084 & 0.082 & 0.106 \\
\hline
\end{tabular}

As it can be seen, taking into account Tab. 1, the temperatures at which a change in activation energy of electrical conductivity takes place correspond to the temperatures of MSPT in Magneli phases $\mathrm{V}_{4} \mathrm{O}_{7}, \mathrm{~V}_{6} \mathrm{O}_{13}$, and $\mathrm{V}_{5} \mathrm{O}_{9}$. For the $\mathrm{V}_{4} \mathrm{O}_{7}$ phase, in addition to the transition from higher to lower activation energy near $T_{t} \sim 240 \mathrm{~K}$, an enough pronounced sharp increase in the electrical conductivity is observed with the temperature increasing. This is typical for the metal-semiconductor phase transition (Fig. 3a). The presence of the contribution of Magneli phases to the electrical conductivity of glass-ceramics on the basis of $\mathrm{VO}_{2}$ with a high copper content ( $8 \mathrm{wt} \%$ or more) indicates that their volume fraction exceeds the percolation threshold. For small additions of $\mathrm{Cu}$, there is no percolation through the Magneli phases and vanadium dioxide provides the main contribution to the electrical conductivity of glass-ceramics.

Thus, the above results and the data of X-ray phase analysis [4] confirm that oxidation-reduction reactions in the liquid phase lead to the crystallization of Magneli phases during the ceramic synthesis in systems $\mathrm{VO}_{2}-\mathrm{VPG}$ and $\mathrm{VO}_{2}-\mathrm{VPG}-\mathrm{SnO}_{2}$ with $\mathrm{Cu}$ and $\mathrm{Cu}_{2} \mathrm{O}$ additives. These phases for small additives of copper (up to $5 \mathrm{wt} \%$ ) are located in the layers of VPG separating $\mathrm{VO}_{2}$ crystallites. Since the Magneli phases in the Tab. 1 go into a conductive state at temperatures substantially lower than the temperature of the MSPT in $\mathrm{VO}_{2}$, they create conductive bonds between $\mathrm{VO}_{2}$ crystallites above $240 \mathrm{~K}$. The developed network of such conductive bonds promote the percolation of electric current through $\mathrm{VO}_{2}$ crystallites ensuring their decisive contribution into electrical properties of 
glass-ceramics and increasing ceramics stability during thermocycling through the temperature of MSPT in vanadium dioxide.
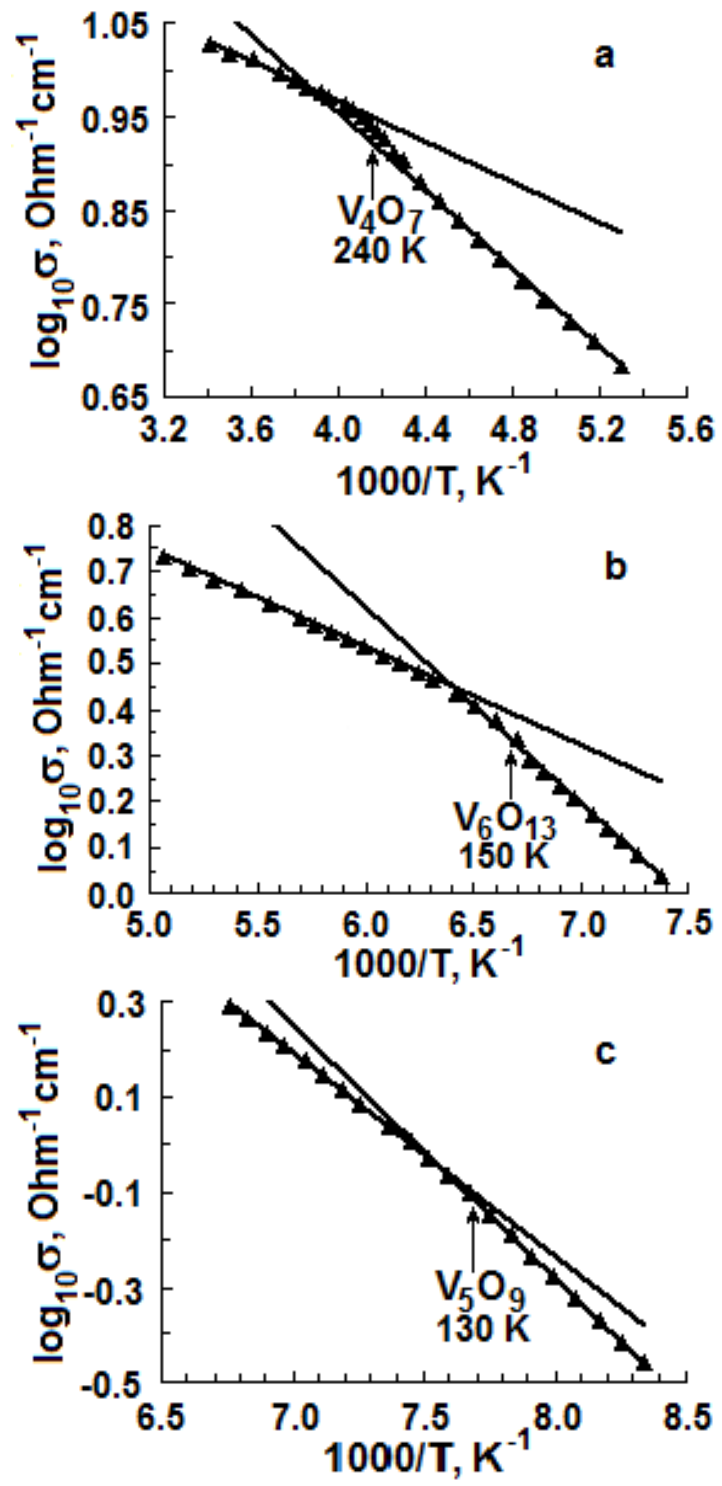

Fig. 3. Temperature dependences of the electrical conductivity of glassceramics $(\mathrm{wt} \%) 40 \mathrm{VO}_{2}-15 \mathrm{VPG}-8 \mathrm{Cu}_{2} \mathrm{O}-37 \mathrm{SnO}_{2}$ near the temperature of metal-semiconductor phase transition in Magneli phases: $\mathrm{a}-\mathrm{V}_{4} \mathrm{O}_{7}$; $\mathrm{b}-\mathrm{V}_{6} \mathrm{O}_{13} ; \mathbf{c}-\mathrm{V}_{5} \mathrm{O}_{9}$

\section{Conclusions}

The electrical conductivity $\sigma$ of glass-ceramics in the systems $\mathrm{VO}_{2}-\mathrm{VPG}$ and $\mathrm{VO}_{2}-\mathrm{VPG}-\mathrm{SnO}_{2}$ with the additives of $\mathrm{Cu}$ and $\mathrm{Cu}_{2} \mathrm{O}$ is studied in the temperature range $77 \mathrm{~K}-400 \mathrm{~K}$.

It is found that a jump of $\sigma$ near the temperature $T_{t}=341 \mathrm{~K}$ of the metalsemiconductor phase transition in $\mathrm{VO}_{2}$ is observed only for glass-ceramic compositions 
containing no more than $5 \mathrm{wt} \%$ of these additives. When their content exceeds $5 \mathrm{wt} \%$, the $\mathrm{VO}_{2}$ content decreases sharply according to the data of differential thermal analysis. The reason for this is the oxidation-reduction reactions between $\mathrm{Cu}$ and $\mathrm{VO}_{2}$ in the liquid phase at ceramics synthesis. These reactions result in the appearance of Magneli phases in glass-ceramics composition. The phase transitions in Magneli phases $\mathrm{V}_{4} \mathrm{O}_{7}, \mathrm{~V}_{5} \mathrm{O}_{9}$, and $\mathrm{V}_{6} \mathrm{O}_{13}$ are detected by the temperature dependence of $\sigma$ as bends of the straight line in coordinates $\log _{10} \sigma \sim 1 / \mathrm{T}$ at the temperatures of MSPT in these phases: $240 \mathrm{~K}, 150 \mathrm{~K}$ and $130 \mathrm{~K}$. The activation energy of conductivity for $\mathrm{T}>\mathrm{T}_{t}$ is lower than for $\mathrm{T}<\mathrm{T}_{t}$, that indicates in a change of the energy structure of zones to the typical for the metalsemiconductor phase transition.

\section{References}

1. Ivon, A.I. Phase composition, microstructure and conductivity of $(85-\alpha) \mathrm{VO}_{2}-15$ (Vanadium-Phosphate-Glass) $-\alpha \mathrm{Cu}$ glass-ceramics / A.I. Ivon, I.M. Chernenko, V.R. Kolbunov // Journal of Non-Crystalline Solids. - 2007.- Vol. 353, No. 16-17. - P. $1521-1528$.

2. Application notes. NTC Inrush Current Limiters. [Electronic resource]: TDK Electronics. - 2019. - Mode access: https://www.tdk-electronics.tdk.com/ download/186012/47c4c7e326bcb6f7d72c41945477a94e/pdf-applicationnotes.pdf

3. Ivon, A.I. Protection of the computer power supply unit against a making current / A.I. Ivon, V.R. Kolbunov, I.M. Chernenko // System Technologies. - 2009. - Issue 5' (64). - P. $80-88$ (in Russian).

4. Kolbunov, V.R. The influence of microstructure and phase composition of glass ceramics in the $\mathrm{VO}_{2}-\mathrm{V}_{2} \mathrm{O}_{5}-\mathrm{P}_{2} \mathrm{O}_{5}-\mathrm{Cu}_{2} \mathrm{O}-\mathrm{SnO}_{2}$ system on the electrical properties related I.M. Chernenko // Ceramics International - 2013. - Vol. 39, No. 4. - P. 3613 - 3620.

5. Bugayev, A.A. Phase transition meta-semiconductor and it application / A.A. Bugayev, B.P. Zakharchenya, F.A. Chudnovskii. - L.: "Nauka", Leningrad department, 1979. -83 p. (in Russian).

6. Tsuchiya, T. Internal friction and electrical properties in phosphate glasses containing transition metal oxides / T. Tsuchiya, M. Otonari, T. Ariyama // Journal of Non-Crystalline Solids. - 1987.- Vol. 95\&96, Part 2. - P. 1001 - 1008.

7. Ivon, A.I. Conductivity stabilization by metal and oxide additives in ceramics on the basis of $\mathrm{VO}_{2}$ and glass $\mathrm{V}_{2} \mathrm{O}_{5}-\mathrm{P}_{2} \mathrm{O}_{5}$ / A.I. Ivon, V.R. Kolbunov, I.M. Chernenko // Journal of Non-Crystalline Solids. - 2005.- Vol. 351, No. 46-48. - P. 3649 - 3654.

8. Ivon, A.I. Determination of the content of crystalline vanadium dioxide in materials based on it / A.I. Ivon, T.A. Bubel // Factory Laboratory. Diagnostics of Materials. - 2005. - Vol. 71, No. 8. - P. 31 - 35 (in Russian).

9. Andreev, V.N. Specific features of the electrical conductivity of $\mathrm{V}_{4} \mathrm{O}_{7}$ single crystals / V.N. Andreev, V.A. Klimov // Physics of the Solid State. - 2009. - Vol. 51, No. 11. - P. $2107-2112$.

10. Höwing, J. Low-temperature structure of $\mathrm{V}_{6} \mathrm{O}_{13} / \mathrm{J}$. Höwing, T. Gustafsson, J.O. Thomas_/ Acta Crystallographica Section B. - 2003. - Vol. B59. - P. 747 - 752.

11. Salker, A.V. Phase transition in $\mathrm{V}_{5} \mathrm{O}_{9} /$ A.V. Salker, H.V. Keer, E.B. Mirza, V.V. Deshpande // Journal of Solid State Chemistry. - 1985. - Vol. 60, No. 11. - P. 135 138. 